\title{
Acute hepatologic and nephrologic effects of calcitriol in Syrian golden hamster (Mesocricetus auratus)*
}

\author{
Ewa Podgorska1, Martyna Sniegocka', Marianna Mycinska²,Wojciech Trybus², Ewa Trybus², \\ Anna Kopacz-Bednarska², Olga Wiechec ${ }^{1}$, Martyna Krzykawska-Serda1 ${ }^{\circledR}$, Martyna Elas ${ }^{1}$, \\ Teodora Krol'2, Krystyna Úrbanska ${ }^{1}$ and Andrzej Slominski ${ }^{3,4}$
}

\begin{abstract}
'Department of Biophysics, Faculty of Biochemistry, Biophysics and Biotechnology, Jagiellonian University in Krakow, Kraków, Poland; 2Department of Cell Biology and Electron Microscopy, Institute of Biology, The Jan Kochanowski University, Kielce, Poland; ${ }^{3}$ Department of Dermatology, Comprehensive Cancer Center, Cancer Chemoprevention Program, University of Alabama at Birmingham, Birmingham, AL, USA; 4VA Medical Center, Birmingham, AL, USA
\end{abstract}

\begin{abstract}
Although vitamin D is included in the group of fat-soluble vitamins, it must be considered as a prohormone. Its active forms, including calcitriol, have pleiotropic effects and play an important role in the regulation of cell proliferation, differentiation and apoptosis, as well as in hormone secretion, and they demonstrate anti-cancer properties. Since calcitriol delivery can be beneficial for the organism, and Syrian golden hamsters represent a unique experimental model, we decided to investigate its toxicity in this species. In this study, we injected calcitriol intraperitoneally at doses 0 (control), $0.180 \pm 0.009$ $\mu \mathrm{g} / \mathrm{kg}$ and $0.717 \pm 0.032 \mu \mathrm{g} / \mathrm{kg}$. Animal behavior was observed for 72 hrs after injection, and afterwards blood, liver and kidneys were collected for post-mortem examination, electron microscopy, and hematology analyses. The highest dose of calcitriol induced a change in animal behavior from calm to aggressive, and the liver surface showed morphological signs of damage. Following injection of calcitriol, ultrastructural changes were also observed in the liver and kidneys, e.g. vacuolization and increased number of mitochondria. There was also a trend for increased serum levels of aspartate aminotransferase (AST), but not of alanine aminotransferase (ALT) or GGTP (gamma-glutamyl transpeptidase). There was no change in $\mathrm{Ca}, \mathrm{Mg}$ and $\mathrm{P}$ levels, as well as in blood morphology between experimental and control groups. These results indicate that calcitriol at 0.717 , but not at $0.180 \mu \mathrm{g} / \mathrm{kg}$, may induce acute damage to the liver and kidneys, without inducing calcemia. We propose that the hepatotoxic effect of calcitriol in hamster constitutes the primary cause of behavioral changes.
\end{abstract}

Key words: calcitriol, Syrian golden hamster, hepatologic toxicity, nephrologic toxicity

Received: 07 April, 2018; revised: 21 May, 2018; accepted: 06 June, 2018; available on-line: 27 August, 2018

e-mail: martyna.krzykawska@uj.edu.pl

*Preliminary data was reported previously at the XLV Winter School of Faculty of Biochemistry, Biophysics and Biotechnology of Jagiellonian University 9-14 February 2018, Zakopane, Poland.

Abbreviations: ALT, alanine aminotransferase; AST, aspartate aminotransferase; ES, Endocrine Society; GGTP, gamma-glutamyl transpeptidase; UVB, ultraviolet B; VDBP, Vitamin D Binding Protein; VDT, Vitamin D Toxicity

\section{INTRODUCTION}

Vitamin D is included in the group of fat-soluble vitamins (Venkatram et al., 2011), but it is also considered to be the oldest hormone in the world associated with a good health status of people, as well as many other forms of life (Holick et al., 2007; Bikle, 2011; Christakos et al., 2016; Piotrowska et al., 2016). The functions of vitamin D and its derivatives are associated not only with calcium and phosphorus homeostasis and the proper functioning of the skeletal system, but also with the regulation of many body systems, including the cardiovascular, endocrine, immune, and central nervous systems as examples (Holick, 2007; Bikle, 2011; Christakos et al., 2016; Rejnmark et al., 2017). The pleiotropic effect is related to the regulation of cell proliferation, differentiation and apoptosis, hormone secretion and other mechanisms (Samuel \& Sitrin, 2008; Burns et al., 2015; Christakos et al., 2016; Piotrowska et al., 2016). Vitamin D is also described in the literature as an anti-cancer agent (Holick, 2007; Battault et al., 2013; Bikle et al., 2013; Slominski et al., 2014; Slominski et al., 2015a; Wierzbicka et al., 2014).

Vitamin D can be delivered to the body in a diet containing cholecalciferol or ergocalciferol, but it is mainly obtained through skin phototransformation of 7-dehydrocholesterol under ultraviolet-B (UVB) radiation (Lips, 2006; Holick, 2007; Bikle, 2011; Henry, 2011). Interestingly, although vitamin $\mathrm{D}$ is important for many organisms (Holick et al., 2007), most furry animals, including dogs, cats or rodents, are not able to effectively and efficiently produce vitamin $\mathrm{D}$ in the skin, hence diet is the primary source of this vitamin for them (Corbee et al., 2008). The 7-dehydrocholesterol present in epidermal cells is transformed into pre-vitamin D3 by absorbing UVB energy by the unsaturated-B ring, and then after thermal reorganization, vitamin D3 is released into the bloodstream (Holick, 2003; Henry, 2011). After binding to the vitamin D Binding Protein (VDBP), it is transported to the liver, where it undergoes the first hydroxylation by CYP2R1 or CYP27A1 to produce calcidiol $(25(\mathrm{OH}) \mathrm{D} 3)$, which is then transported to the kidneys, where it is hydroxylated to the active form of calcitriol $\left(1,25(\mathrm{OH})_{2} \mathrm{D} 3\right)$ (Reichrath et al., 2007; Lehmann \& Meurer, 2010; Bikle, 2014). Alternative pathways of vitamin $\mathrm{D}$ activation by CYP11A1, a rate limiting enzyme of steroidogenesis, have recently been described (Slominski et al., 2005, 2012, 2015b, 2015c). The products of that pathway are biologically active, and act on vitamin $\mathrm{D}$ receptor (VDR) and retinoic orphan acid receptors (RORs) (Slominski et al., 2014; Slominski et al., 2017a; Slominski et al., 2017b).

Currently, it is estimated that vitamin D deficiency affects up to one billion people around the world (Mazahery \& Hurst, 2015). According to the Endocrine So- 
ciety (ES), it is assumed that deficiency corresponds to a $25(\mathrm{OH}) \mathrm{D}$ serum concentration below $20 \mathrm{ng} /$

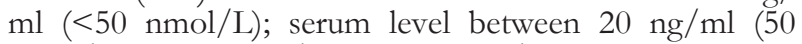
$\mathrm{nmol} / \mathrm{L})$ and $30 \mathrm{ng} / \mathrm{ml}(<75 \mathrm{nmol} / \mathrm{L})$ is considered as insufficiency; while levels above $30 \mathrm{ng} / \mathrm{ml}$ (>75 nmol/L) are sufficient to maintain normal physiological functions (Gupta et al., 2014; Sowah et al., 2017). Although the active form of this vitamin is its metabolite $1,25(\mathrm{OH})_{2} \mathrm{D} 3$, the determination of the vitamin D status is not based on the measurement of its serum concentration (Thacher \& Clarke, 2011). Metabolite $25(\mathrm{OH}) \mathrm{D}$ is used for that purpose, whose half-life in human serum is about 2-3 weeks (Holick, 2009; Thacher \& Clarke, 2011).

Interestingly, vitamin D toxicity (VDT), also known as hypervitaminosis D, is a rare complication (Marins et al., 2014; Marcinowska-Suchowierska et al., 2016). As our body can regulate the amount of vitamin $\mathrm{D}$ produced during sun exposure, and enriched foods do not contain large amounts of this compound (Gupta et al., 2014), poisoning will not occur because the excess of vitamin D3 and its precursor is photodegradable, as proposed by many authors (Alshahrani \& Aljohani, 2013; Wacker \& Holick, 2013). Vitamin D may also follow alternative pathways of activation in the skin or in organs expressing high systemic levels of CYP11A1 (Slominski et al., 2012; Slominski et al., 2015c; Slominski et al., 2018). However, excessive oral intake of artificial supplements may lead to such excess (Marins et al., 2014; Marcinowska-Suchowierska et al., 2016). Especially nowadays, high doses of vitamin D are sold without prescription, which can lead to patients taking excessive amounts of vitamin D supplements (Gorris et al., 2016). The main and most frequently reported clinical consequence of vitamin D toxicity is hypercalcemia (Holick, 2007; Chakraborty et al., 2015). The probable mechanism of vitamin D toxicity is related to a signal transduction process, and the fact that the catabolic system and CYP24A1 are not able to keep up with the target calcitriol cell levels (Koul et al., 2011). Early symptoms of vitamin D toxicity include, among others, nausea, diarrhoea, anorexia, bone pain, drowsiness, constant headaches, irregular heartbeat and hypertension, loss of appetite, muscle and joint pain, and also nervousness (Schwalfenberg, 2007; Alshahrani \& Aljohani, 2013; Virmani, 2014).

Since an increased calcitriol uptake can be beneficial for organisms, we decided to study the toxicity of vitamin D active form in hamsters. In our study we focused our interest on behavioral observation, hematology, internal organ function and morphology.

\section{MATERIALS AND METHODS}

Animals. This experiment was performed using 12 female Syrian golden hamsters (22-23 months old) purchased at the Charles River Laboratories. The experiments on animals were approved by the Local Institutional Animal Care and Use Committee, approval No. 264/2015. The animals were maintained under sterile conditions in a ventilated cabin equipped with HEPA filters, in a $12 \mathrm{~h}$ light cycle, with free access to water and food. The detailed composition of the feed (the Labofeed B standard, Wytwornia Pasz "Morawski", Kcynia, Poland) is presented in the Supplementary Fig. S1 (at www.actabp.pl).

Calcitriol treatment. Calcitriol $\left(1,25(\mathrm{OH})_{2} \mathrm{D} 3\right)$ was purchased from Sigma-Aldrich. First, vitamin D was dissolved in $100 \%$ ethanol to $100 \mu \mathrm{M}$. Then it was diluted in PBS to $50 \mathrm{nM}$ (final ethanol concentration was $0.05 \%)$ and $200 \mathrm{nM}(0.20 \%$ final ethanol concentration) to a total injectable volume of $2 \mathrm{ml}$. The doses of $50 \mathrm{nM}$ and $200 \mathrm{nM}$ calcitriol per kilogram body weight were $0.180 \pm 0.009 \mu \mathrm{g} / \mathrm{kg}$ and $0.717 \pm 0.032 \mu \mathrm{g} /$ $\mathrm{kg}$, respectively. Four hamsters treated with the vehicle (PBS plus ethanol) served as controls. All injections were intraperitoneal. Animal behavior was recorded daily (the characteristic pain symptoms were under special investigation, e.g. the eye shape, fur condition, ear position, socialization, and hyperactivity), and the Syrian golden hamsters were euthanized 72 hours after $1,25(\mathrm{OH})_{2} \mathrm{D} 3$ or vehicle administration.

Post-mortem examination. Syrian golden hamsters were euthanized by injection of a mixture of drugs (ketamine and xylazine, $150 \mathrm{mg} / \mathrm{kg}$ and $10 \mathrm{mg} / \mathrm{kg}$, respectively, ip injection). Their blood was drawn from the ventricles of a beating heart. The livers and kidneys were also collected, grossly inspected, weighed and prepared for further examination.

Tissue preparation for transmission electron microscopy. Tissue fragments were fixed in 3\% glutaraldehyde, followed by contrasting with $2 \% \mathrm{OsO}_{4}$ (SPI Supplies, USA), and then immersed in epoxy resin Epon 812 (Serva, Germany). The protocol used was a modified method of Marzella and Glaumann (1980) (Marzella \& Glaumann, 1980). Ultrathin slices were prepared using the ultramicrotome Leica EM UC7. Photographs were taken using the transmission electron microscope Tecnai G2 Spirit (FEI Company, USA).

Hematology analysis. Blood morphology and biochemical parameters were analyzed for 12 animals using the hematological analyzer Cobas e 411 (Roche). Immunoenzymatic assay methods with appropriate reagent kits were used. The Elecsys Vitamin D Total test, involving the "ECLIA" electrochemiluminescence method, was used for determination of 25-hydroxyvitamin D levels in hamster serum. Hamster blood was sampled from the beating heart into vials with $\mathrm{K}_{3}$ EDTA. Blood smears were performed for all samples, and stained using the Pappenheim method (May Grunwald-Giemza, AQUAMED, Kraków, Poland). Microscopic analysis of blood cells was carried out using immersion under magnification of 1000x, and calculated using Shilling's formula (Krawczyński \& Osiński, 1967).

Statistics and data analysis. Statistica $12^{\circledR}$ software (StatSoft, Tulsa, USA) was used to analyze the experimental results. The Syrian golden hamsters were divided into fully randomized groups. One-way ANOVA, U-test and Fisher test were performed on a needs basis. During analysis, all data were correlated together to investigate the possible reasons for data heterogeneity.

\section{RESULTS}

\section{Animal behavior and macroscopic observation during necropsy}

All animals treated with a high dose of calcitriol were nervous and overreactive. During they long-term stay in the animal facility, untreated animals were calm and well-adjusted to handlers. In contrast, agitated and aggressive behavior towards handlers was observed after a single dose of calcitriol $(0.717 \mu \mathrm{g} / \mathrm{kg})$. Animal weight has not changed throughout the experiment. The quantified information about the change in hamster behavior after calcitriol treatment in comparison to the control is shown in Table 1. 
Table 1. The table presents behavioral changes and macroscopic changes in the liver according to the calcitriol doses.

The behavior is presented on a scale of $0-1$, where $0=$ calmness; $1=$ aggressiveness. Changes in the liver are shown on a scale of $0-2$, where $0=$ no change; $1=$ small cysts; 2 = large cysts. Average values $\pm S D$ illustrating the liver changes for calcitriol doses $0 \mathrm{nM}, 50 \mathrm{nM}$ and $200 \mathrm{nM}$ were $0 \pm 0,0 \pm 0$ and $1.25 \pm 0.50$, respectively. The ANOVA test showing statistical significance for the highest dose of calcitriol as compared with the control group was $p=0.024$.

\begin{tabular}{|c|c|c|c|}
\hline Calcitriol dose [nM] & Animal code & Behavior & Changes on the liver \\
\hline \multirow{4}{*}{0} & 1 & 0 & 0 \\
\hline & 2 & 0 & 0 \\
\hline & 3 & 0 & 0 \\
\hline & 4 & 0 & 0 \\
\hline \multirow{4}{*}{50} & 5 & 0 & 0 \\
\hline & 6 & 0 & 0 \\
\hline & 7 & 0 & 0 \\
\hline & 8 & 0 & 0 \\
\hline \multirow{4}{*}{200} & 9 & 1 & 1 \\
\hline & 10 & 1 & 1 \\
\hline & 11 & 1 & 1 \\
\hline & 12 & 1 & 2 \\
\hline
\end{tabular}

Table 2. The mean values $(n=4)$ for liver function tests, depending on the dose of calcitriol $(A)$.

The chart presents the dependence of aspartate aminotransferase (AST) levels on the calcitriol dose for individual animals.

\begin{tabular}{lccc}
\hline \multirow{2}{*}{ Dose of calcitriol $[\mathrm{nM}]$} & & Parameters & GGTP [U/I] \\
\cline { 2 - 4 } & ALT [U/I] & AST [U/I] & $1.25 \pm 0.96$ \\
\hline 0 & $38.00 \pm 4.8$ & $41.5 \pm 11.21$ & $0.75 \pm 1.5$ \\
\hline 50 & $42.75 \pm 20.22$ & $55.5 \pm 18.91$ & $0.5 \pm 0.58$ \\
\hline
\end{tabular}

In animals without calcitriol treatment, as well as in the group of hamsters injected with $50 \mathrm{nM}$ calcitriol, there were no macroscopic changes found in the liver. However, after the highest dose of calcitriol, cystic changes in the liver were observed at the macroscopic level. There were no changes in the liver weight between the control and experimental groups. Statistical analysis (Anova univariate) showed no significant difference in the weight of the livers of animals from individual experimental groups. Mean liver weight values are presented in the Supplementary Fig. S2 (at www.actabp.pl).

\section{Blood and serum effects}

To find an explanation for observed behavior changes, blood samples were analyzed. The levels of $\mathrm{Ca}$ (calcium), $\mathrm{P}$ (phosphate) and $\mathrm{Mg}$ (magnesium) were unaffected by calcitriol treatment (Fig. S3, Table S1 at www.actabp.pl). No significant changes in the hematological parameters were found (Fig. S3, Table S2 and S3 at www.actabp. pl). Red blood cell parameters and leukocyte characteristics were within the normal range for a healthy hamster (Weiss \& Wardrop, 2010; Suckow et al., 2012), although they were at the upper limit for each group. Mean values are presented in the Supplementary Fig. S3 (at www. actabp.pl).

\section{Level of calcidiol in the blood}

To compare our results with the gold-standard clinical test for vitamin $\mathrm{D}$ body level, the calcidiol blood concentration was measured. The level of $25(\mathrm{OH}) \mathrm{D} 3$ was measured in the hamster blood 3 days after the single, intraperitoneal injection of calcitriol. No significant changes were registered between the vehicle control $(14.96 \pm 2.24$ $\mathrm{ng} / \mathrm{ml}$ ) and experimental groups that received 50 and $200 \mathrm{nM}$ of calcitriol (16.33 \pm 2.97 and $15.26 \pm 4.70 \mathrm{ng} / \mathrm{ml})$.

\section{Biochemical effects}

Liver toxicity was characterized by biochemical parameters. There was only a slight increase in the alanine aminotransferase (ALT) after calcitriol treatment, which was

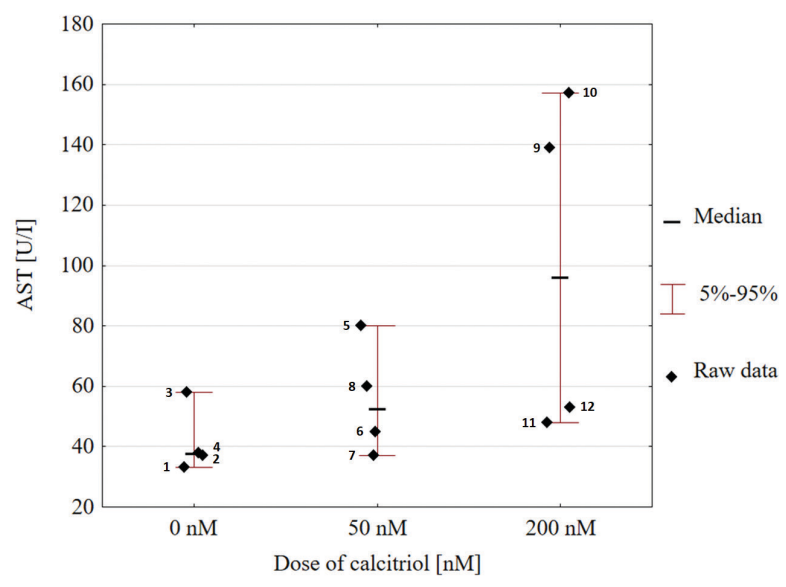

Figure 1. The increase in AST due to calcitriol treatment dose was estimated to have the following effect: $F(2,9)=2.93520$, $p=0.10439$, and significant intercept $(p=0.0001)$.

The point labels indicate the animal code. A considerable heterogeneity of AST values was observed for hamsters treated with 200 $\mathrm{nM}$ calcitriol solution. The variances differed between the calcitriol dose groups ( $p$-value of Fisher test for dose $50 \mathrm{nM}$ and $200 \mathrm{nM}$ relative to control was 0.1048 and 0.6571 , respectively, which indicated a statistical difference between variances of the individual samples). 

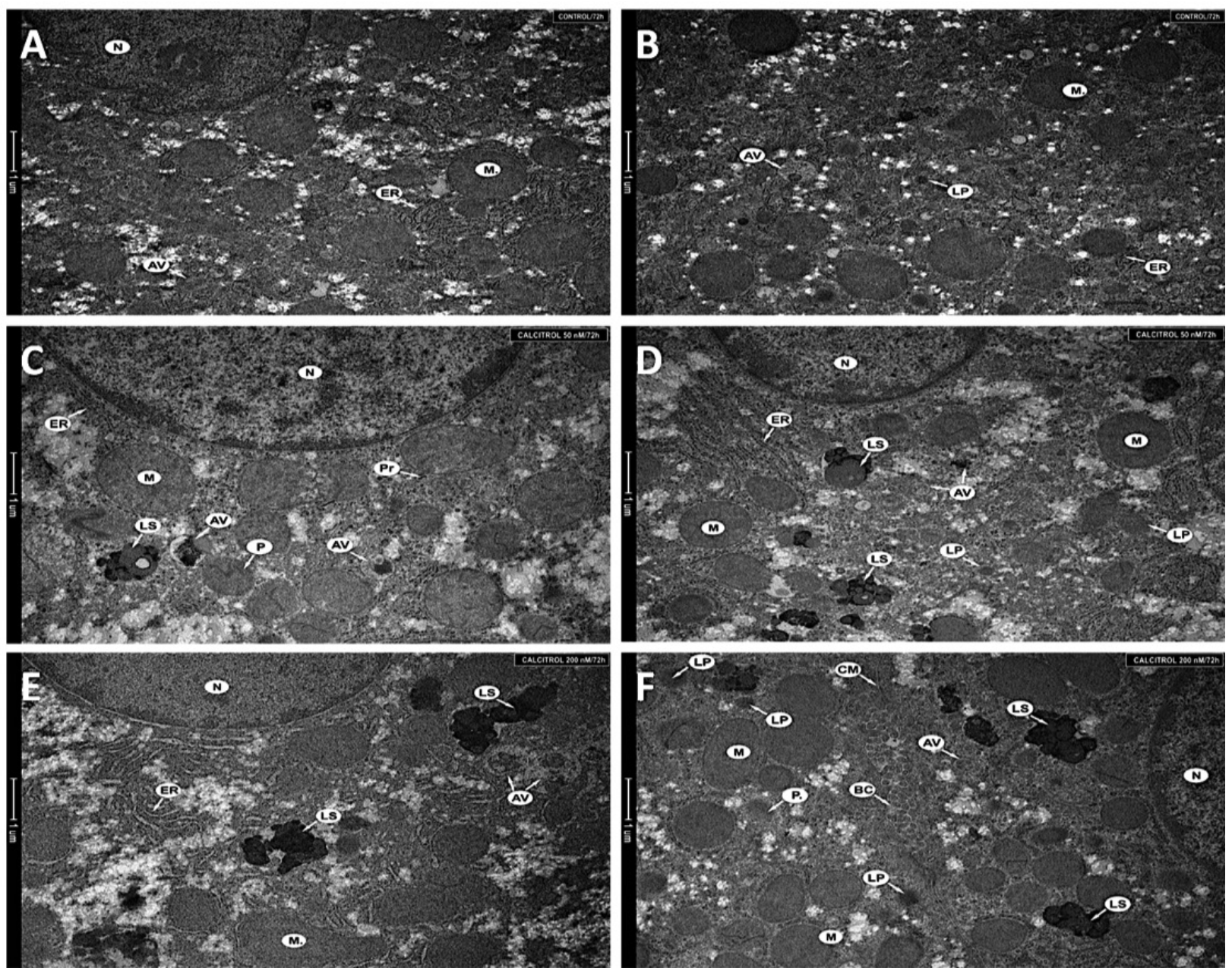

Figure 2. Fragments of a hepatocyte from liver (A, B) of an untreated animal, (C, D) of a hamster treated with $50 \mathrm{nM},(\mathrm{E}, \mathrm{F})$ of a hamster treated with $200 \mathrm{nM}$.

Nucleus $(N)$, mitochondria $(M)$, rough endoplasmic reticulum (ER), single autophagic vacuoles (AV), primary lysosomes (LP), peroxisomes $(\mathrm{P})$, secondary lysosomes (LS), polyribosomes $(\mathrm{Pr})$, cellular membrane (CM), and bile duct $(\mathrm{BC})$ were seen in the cytoplasm. Magnification $11500 \times(A-F)$

statistically insignificant. An increase in the aspartate aminotransferase (AST) values was observed for two experimental groups as compared with the untreated control (ANOVA intercept $p=0.0001$ ). There was a higher than a two-fold increase in the mean AST values between the control group and the group treated with the highest dose of calcitriol. The levels of gamma-glutamyl transpeptidase (GGTP) were reduced in experimental groups in comparison to the control, however, the changes were not statistically significant. Mean values \pm S.D. of liver function tests are presented in Table 2. The dependence of AST levels on the administered calcitriol dose in individual animals is presented in Fig. 1. The above analysis indicates an enhanced liver activity (Supplementary Fig. S4 at www.actabp.pl).

\section{Ultrastructural effects in the liver after calcitriol treatment}

Numerous normal organelles, with proper structure and size, were observed in the hepatocytes of the untreated animals. Normal nucleus, cisterns of rough endoplasmic reticulum, primary lysosomes, single vacuoles and mitochondria were observed (Fig. $2 \mathrm{~A}$ and $2 \mathrm{~B}$ ).

In comparison, the ultrastructure of hepatocytes obtained from animals treated with calcitriol at $50 \mathrm{nM}$ has changed (Fig. 2C and 2D). Specifically, there was a slight increase in the number and size of mitochondria. Moreover, a distinct enlargement of the lysosomal system was seen (Fig. 2C and 2D) and there was formation of autophagic vacuoles at different stages of development.

The ultrastructure of hepatocytes from the livers of hamsters treated with $200 \mathrm{nM}$ was substantially changed (Fig. 2E and 2F). Mitochondria were more numerous, enlarged and with a changed structure. Moreover, the mitochondria were often surrounded by the membrane of the endoplasmic reticulum, indicating progressing vacuolization. Other findings included an increased number of lysosomes, numerous autophagic vacuoles, and a slight swelling of the rough endoplasmic reticulum (Fig. 2E).

\section{Ultrastructural effects in the kidney after calcitriol treatment}

Normal organelles of proper size and structure were seen in the kidney cells obtained from untreated animals. Figs $3 \mathrm{~A}$ and $3 \mathrm{~B}$ show the nucleus, mitochondria, primary lysosomes, Golgi apparatus and single vacuoles. The low dose of calcitriol $(50 \mathrm{nM})$ already caused an increase in the number and size of mitochondria, as well as the presence of many ribosomes and polyribosomes (Figs 3C and 3D). Calcitriol also led to a distinctive increase of the lysosomal compartment, and to generation 

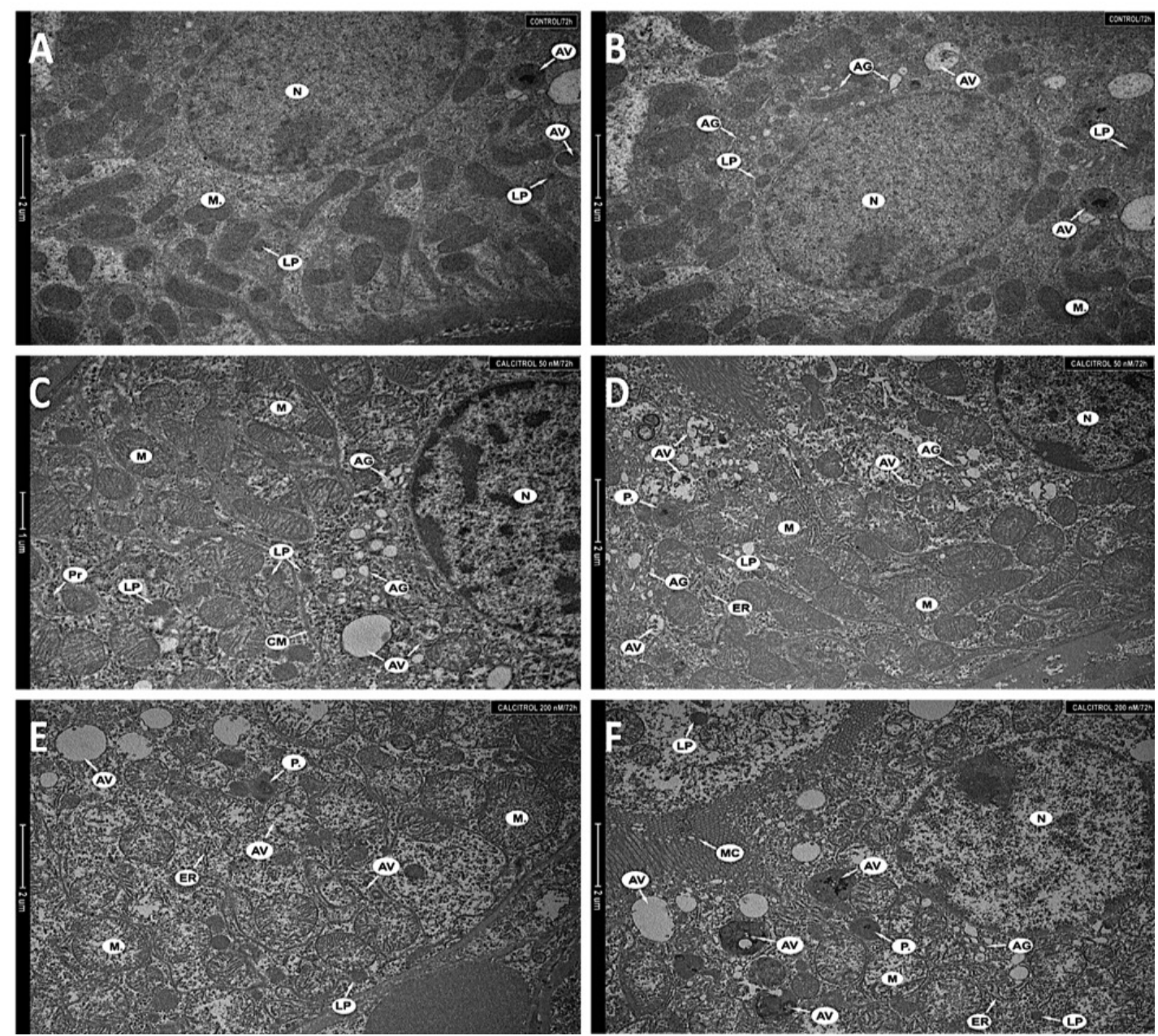

Figure 3. Fragments of the kidney cells (A, B) of an untreated animal, (C, D) of a hamster treated with $50 \mathrm{nM},(\mathrm{E}, \mathrm{F})$ of a hamster treated with $200 \mathrm{nM}$.

Nucleus $(N)$, mitochondria $(M)$, single autophagic vacuoles (AV), primary lysosomes (LP), Golgi apparatus (AG), polyribosomes (Pr), cell membrane (CM), endoplasmic reticulum (ER), peroxisomes (P.) and microvilli (MC). Magnification 8 200× (A, B, D-F), 9 900× (C).

of various autophagic vacuoles at different stages of development. Close to the nucleus, more swollen Golgi apparatus cisterns were detected.

The higher dose of calcitriol $(200 \mathrm{nM})$ induced substantial changes in the ultrastructure of kidney cells in comparison to the control group. Both, the size and number of mitochondria increased, and shortened mitochondrial cristae were observed. Mitochondrial swelling was also seen (Fig. 3E). A substantial increase in the number of lysosomes, and numerous various autophagic vacuoles, as well as autophagolysosomes was characteristic for autophagy. Cellular response in the kidney to the increased dose of calcitriol is shown in Figs $3 \mathrm{E}$ and $\mathrm{F}$, presenting the enhanced lysosomal system and increased number of peroxisomes.

\section{DISCUSSION}

The most important message from our study is vitamin $\mathrm{D}$ toxicity (unrelated to the calcium and magnesium blood levels) in older Syrian golden hamsters. The observed effect was demonstrated by changes on the macro- and micro-scale (e.g. liver cysts, increase in the number and size of mitochondria in livers and kidneys), and by the pain-related behavioral changes.
We found that the observed nervousness and hyperactivity in animals had been related to the highest injected dose of calcitriol (200 nM). The reasons behind such behavior were not clear. However, it appeared to be a typical behaviour of Syrian golden hamsters in response to pain. Additionally, during the necropsy examination, significant changes in liver morphology were observed (e.g. cysts). Moreover, our further analysis strongly indicated the presence of hepatotoxic effects of calcitriol. Therefore, we postulate that severe liver pain after a high dose of calcitriol may be responsible for the observed changes in animal behavior. Additionally, liver damage might have induced the itching of the skin, which would explain the nervousness of the animals while handling.

Due to the fact that several steps of vitamin $\mathrm{D}$ metabolism, and its binding to specific proteins, depend on magnesium as a cofactor (Gröber et al., 2015), administration of high doses of vitamin $\mathrm{D}$ leads to depletion of magnesium (Reddy \& Edwards, 2017). However, in the current study, tests did not reveal a reduction in magnesium levels in any of the animal groups. Due to a common problem with the availability of tests determining the exact level of magnesium, the results could have been overestimated. It should be noted though, that even if the results represent normal levels of magnesium 
in plasma, there may still be an intracellular deficiency of it (Reddy \& Edwards, 2017).

Based on vitamin D metabolism pathway in the body, the finding of no significant changes in calcidiol $(25(\mathrm{OH}) \mathrm{D} 3)$ blood concentration in all of experimental groups may be treated as a proof of concept for our experiment, where calcitriol $\left(1,25(\mathrm{OH})_{2} \mathrm{D} 3\right)$ was injected into the animals. The level of $25(\mathrm{OH}) \mathrm{D} 3$ is related to the liver metabolism, whereas $1,25(\mathrm{OH})_{2} \mathrm{D} 3$ blood level is associated with kidney function, and depends on the $25(\mathrm{OH}) \mathrm{D} 3$ level. In our case, the assumption can be made that the self-produced $1,25(\mathrm{OH})_{2} \mathrm{D} 3$ is similar in all experimental groups (based on $25(\mathrm{OH}) \mathrm{D} 3$ levels), and the difference in calcitriol levels is only due to the injected amount.

However, the morphological defects in the liver appear to be confirmed by selected biochemical parameters only. Thus, a more than two-fold increase was observed for the AST levels in hamsters given $200 \mathrm{nM}$ of calcitriol as compared with the untreated group, which might indicate liver damage resulting from the administration of calcitriol, considering the function of AST. ALT and AST are enzymes that are found especially in the liver and skeletal muscles, but in other organs as well. Elevated enzyme levels are seen, inter alia, in hamsters with hepatic necrosis, affected hepatocytes or liver neoplasia and metabolic alterations (Suckow et al., 2012). The ratio of AST to ALT is more clinically useful, and it is calculated if the normal ranges for those enzymes are exceeded. Ratios higher than 1 indicate liver disease, while ratios greater than 2 are observed in toxic damage, e.g. in alcoholic hepatitis (Gowda et al., 2009). Interestingly, the mean ratio of AST to ALT in animals injected with $200 \mathrm{nM}$ of calcitriol was close to 2, while for the control group it was almost 1. Those results can be explained by two factors: (1) age of the tested animals, and (2) ethanol concentration in the injected solution. Namely, hamsters metabolize ethanol very well and very quickly. This serves as protection against liver damage, and most probably results from an evolutionary adaptation associated with the necessity of consuming fermented grains stored in damp burrows (McPherson \& Van Hoosier, 1987). Liver changes can be also associated with aging (Suckow et al., 2012). However, the effect of aging was excluded, because all hamsters in both, the control group and the experimental groups, were of similar age, and in animals without calcitriol, no changes in the liver were observed. Although in the control group the AST level was slightly raised in comparison to young animals, a significant increase in the level of the parameters was observed only after calcitriol administration. Therefore, we postulate that the observed liver damage is directly related to calcitriol supplementation.

Furthermore, liver damage is usually accompanied by an increase in the gamma-glutamyl transpeptidase levels (Gowda et al., 2009). However, the study presented here reveals a slightly reduced, but statistically not significant effect observed with increased doses of calcitriol. This suggests a lack of bile duct damage resulting from the calcitriol doses used.

The possibility of observing changes in organs under the influence of vitamin $\mathrm{D}$ is also interesting in view of the results presented in the publication of McCullough and coworkers in 2010 (McCullough et al., 2010). Results from epidemiologic studies presented in that work showed that a high dose of $25(\mathrm{OH}) \mathrm{D}$ was associated with a two-fold higher risk of developing pancreatic cancer (McCullough et al., 2010).
The recognised toxicity of vitamin D is hypercalcemia (Slominski et al., 2010, 2011; Wang et al., 2012; Cheng et al., 2014). However, the presented analyses demonstrate a lack of effect on calcium levels. According to the literature, calcium levels for healthy hamsters should fall within the range of $5.3-12.0 \mathrm{mg} / \mathrm{dl}$ (Suckow et al., 2012); the calcium levels obtained in both, the control and experimental groups, were slightly above that limit. For the control group, the mean value was $13.97 \pm 0.97$, while for the groups treated with $50 \mathrm{nM}$ and $200 \mathrm{nM}$ of calcitriol, it was $13.80 \pm 0.85$ and $14.53 \pm 1.23$, respectively, hence no hypercalcemia could be observed after the administration of calcitriol in the tested hamsters. The level of $\mathrm{Ca}$ in serum could be affected by the age of hamsters used in the experiment. It is known that older animals may present with calcium metabolism disorders, which are the result of hormonal disturbances related to age, especially in females (Yeh et al., 2013). Finally, standardization of the $\mathrm{Ca}$ assay used in the study may be different from those previously reported (Suckow et al., 2012), thus leading to a higher reading in the control values. Nevertheless, the data we present clearly indicate a lack of effect of the injected calcitriol doses on plasma calcium and phosphate levels.

Ultrastructural examination of the livers demonstrated an effect of calcitriol. Namely, normal organelles were observed in the hepatocytes of the untreated animals, while changes were seen in the hepatocytes obtained from animals treated with calcitriol dosed at 50 $\mathrm{nM}$ and $200 \mathrm{nM}$. For example, generation of various autophagic vacuoles at different stages of development, and enlargement of the lysosomal system, following the administration of the $50 \mathrm{nM}$ calcitriol dose indicate the induction of autophagy as an adaptive cellular response to calcitriol treatment. The higher dose of calcitriol also led to the induction of structures typical of autophagy, i.e. primary and secondary lysosomes, and autophagic vacuoles (containing material at various stages of degradation). The observed effects could indicate distress induced by calcitriol on cellular metabolism, exemplified by the changes in mitochondria, and lysosomal activities.

Ultrastructural effects after calcitriol treatment were also investigated in the kidneys. While kidney cells from untreated animals showed normal organelles (proper size and structure), the same structures were altered in animals treated with calcitriol. Following injection of the lower dose of calcitriol, the changes indicated induction of autophagy as an adaptive response of kidney cells to calcitriol. However, effects after the dose of $200 \mathrm{nM}$, such as swelling of the mitochondria, suggested a metabolic effect in response to calcitriol. Cellular response in the kidneys to an increased dose of calcitriol consists of defense mechanisms' activation. The changes in the kidneys might be secondary to an inadequate liver metabolism of calcitriol.

To eliminate other reasons for the observed change in animal behavior, an alternative hypothesis was tested. That is why the level of available magnesium, called 'the sedative ion' (DiSilvestro, 2005), was measured. In magnesium deficiency, the activation of calcium channels decreases, leading to an increase in the calcium concentration in the cell, and later to a reduced axon stimulation threshold, which then results in an increase in neuromuscular excitability (Mawri et al., 2017). However, in our experiment, no significant differences in magnesium and calcium levels were detected. 


\section{CONCLUSION}

Our results indicate that the tested doses of calcitriol may lead to acute effects on the liver and kidneys. The hepatotoxic effect of calcitriol in Syrian golden hamster can be painful, and seems to be a primary cause of changes in the animal behavior.

Our findings suggest that animal age may be an important factor for vitamin $\mathrm{D}$ toxicity due to acute effects on the liver, without related changes in the calcium level. The significant changes in animal behavior were related to calcitriol uptake.

\section{Conflicts of interests}

The authors declare that they have no conflicts of interests.

\section{Acknowledgement of Financial Support}

Supported by grant no UMO-2012/07/B/NZ4/01657 to KU from Polish National Science Centre. Faculty of Biochemistry, Biophysics, and Biotechnology of the Jagiellonian University is a partner of the Leading National Research Center (KNOW) supported by the Ministry of Science and Higher Education. Partial support from NIH grants R21AR066505, 1R01AR071189-01A1 and 1R01AR073004-01A1 to AS is also acknowledged.

\section{REFERENCES}

Alshahrani F, Aljohani N (2013) Vitamin D: Deficiency sufficiency and toxicity. Nutrients 5: 3605-3616. doi: 10.3390/nu5093605

Battault S, Whiting S. J, Peltier S. L, Sadrin S, Gerber G, Maixent JM (2013) Vitamin D metabolism functions and needs: From science to health claims. Eur I Nutrit 52: 429-441. doi: 10.1007/s00394-0120430-5

Bikle DD (2011) Vitamin D: an ancient hormone. Exp Dermatol 20: 7-13

Bikle DD (2014) Vitamin D metabolism mechanism of action and clinical applications. Chem Biol 21: 319-329. doi: 10.1016/j.chembiol.2013.12.016

Bikle DD, Elalieh H, Welsh J, Oh D, Cleaver J, Teichert A (2013) Protective role of vitamin D signaling in skin cancer formation. I Steroid Biochem Mol Biol 136: 271-279. doi: 10.1016/j.jsbmb.2012.09.021

Burns EM, Elmets CA, Yusuf N (2015) Vitamin D and skin cancer. Photochem Photobiol 91: 201-209. doi: 10.1111/php.12382

Chakraborty S, Sarkar AK, Bhattacharya C, Krishnan P, Chakraborty S (2015) A nontoxic case of vitamin D toxicity. Lab Med 46: 146-149. doi: 10.1309/LM5URN1QIR7QBLXK

Cheng CYS, Slominski AT, Tuckey RC (2014) Metabolism of 20-hydroxyvitamin D3 by mouse liver microsomes. I Steroid Biochem Mol Biol 144: 286-293. doi: 10.1016/j.jsbmb.2014.08.009

Christakos S, Dhawan P, Verstuyf A, Verlinden L, Carmeliet G (2016) Vitamin D: metabolism molecular mechanism of action and pleiotropic effects. Physiol Rev 96: 365-408. doi: 10.1152/physrev.00014.2015

Corbee RJ, Vaandrager AB, Kik MJ, Molenaar MR, Hazewinkel HAW (2008) Cutaneous vitamin D synthesis in carnivorous species. Eur Soc Vet Comp Nutrit 96: 1

DiSilvestro RA (2005) Handbook of Minerals as Nutritional Supplements. CRC Press. doi: 10.1080/10715760500510437

Gorris MA, Arora H, Lieb DC, Aloi JA (2016) A word of caution when prescribing high dose vitamin D. Am J Med 130: e129-e130. doi: 10.1016/j.amjmed.2016.10.025

Gowda S, Desai PB, Hull VV, Math AK, Vernekar SN, Kulkarni SS (2009) A review on laboratory liver function tests. Pan African Med J 3: 17. doi: 10.11604/pamj.2009.3.17.125

Gröber U, Schmidt J, Kisters K (2015) Magnesium in prevention and therapy. Nutrients 7: 8199-8226. doi: 10.3390/nu7095388

Gupta AK, Jamwal V, Sakul, Malhotra P (2014) Hypervitaminosis D and systemic manifestations: A comprehensive review. I Inte Med Scl Acad 27: 236-237

Henry HL (2011) Regulation of vitamin D metabolism. Best Practice Res Clin Endocrinol Met 25: 531-541. doi: 10.1016/j.beem.2011.05.003

Holick MF (2003) Vitamin D: A millenium perspective. J Cell Biochem 88: 296-307. doi: 10.1002/jcb.10338

Holick M. F (2007) Vitamin D Deficiency New England Journal of Medicine 357(3) 266-281. doi: 10.1056/NEJMra070553
Holick MF (2009) Vitamin D status: measurement interpretation and clinical application. Ann Epidemiol 19: 73-78. doi: 10.1016/j.annepidem.2007.12.001

Holick MF, Chen TC, Lu Z, Sauter E (2007) Vitamin D and skin physiology: A D-lightful story. J Bone Mineral Res 22 (Suppl 2): 2833. doi: 10.1359/jbmr.07s211

Koul PA, Ahmad SH, Ahmad F, Jan RA, Shah SU, Khan UH (2011) Vitamin D toxicity in adults: A case series from an area with endemic hypovitaminosis D. Oman Med J 26: 201-204. doi: 10. 5001/ omj.2011.49

Krawczyński J, Osiński T (1967) Laboratoryjne metody diagnostyczne. Warszawa: PZWL (in Polish)

Lehmann B, Meurer M (2010) Vitamin D metabolism. Dermatol Therapy 23: 2-12. doi: 10.1111/j.1529-8019.2009.01286.x

Lips P (2006) Vitamin D physiology. Progress Biophys Mol Biol 92: 4-8. doi: 10.1016/j.pbiomolbio.2006.02.016

Marcinowska-Suchowierska E, Płudowski P, Witaminą Z, Tałałaj M (2016) Vitamin D toxicity. Post N Med XXIX(10) 756-759

Marins TA, Galvão T de FG, Korkes F, Malerbi DAC, Ganc AJ, Korn D, Wagner J, Guerra JC de C, Borges Filho WM, Ferracini FT, Korkes H (2014) Vitamin D intoxication: case report. Einstein (São Paulo) 12: 242-244. doi: 10.1590/S1679-45082014RC2860

Marzella L, Glaumann H (1980) Increased degradation in rat liver induced by vinblastine. II. Morphologic characterization. Lab Invest J Tech Methods Pathol 42: 18-27

Mawri S, Gildeh E, Joseph N, Rabbani B, Zweig B (2017) Cardiac dysrhythmias and neurological dysregulation: manifestations of profound hypomagnesemia. Case Reports Cardiol Hindawi 2017 1-5. doi: $10.1155 / 2017 / 6250312$

Mazahery H, von Hurst PR (2015) Factors affecting 25-hydroxyvitamin $\mathrm{D}$ concentration in response to vitamin D supplementation. Nutrients 7: 5111-5142. doi: 10.3390/nu7075111

McCullough ML, Weinstein SJ, Freedman DM, Helzlsouer K, Flanders WD, Koenig K, Kolonel L, Laden F, Le Marchand L, Purdue M, Snyder K, Stevens VL, Stolzenberg-Solomon R, Virtamo J, Yang G, Yu K, Zheng W, Albanes D, Ashby J, Bertrand K, Cai H, Chen Y, Gallicchio L, Giovannucci E, Jacobs EJ, Hankinson SE, Hartge P, Hartmuller V, Harvey C, Hayes RB, Horst RL, Shu XO (2010) Correlates of circulating 25 -hydroxyvitamin $\mathrm{D}$ : cohort consortium vitamin D pooling project of rarer cancers. Am J Epidemiol 172: 21-35. doi: $10.1093 /$ aje/kwq113

McPherson CW, Van Hoosier GL (1987) Laboratory hamsters. McPherson CW, Van Hoosier GL eds. Orlando: Academic Press

Piotrowska A, Wierzbicka J, Ślebioda T, Woźniak M, Tuckey RC, Slominski AT, Żmijewski MA (2016) Vitamin D derivatives enhance cytotoxic effects of $\mathrm{H}_{2} \mathrm{O}_{2}$ or cisplatin on human keratinocytes Steroids 110: 49-61. doi: 10.1016/j.steroids.2016.04.002

Piotrowska A, Wierzbicka J, Zmijewski MA (2016) Vitamin D in the skin physiology and pathology. Acta Biochim Pol 63: 17-29. doi: 10.18388/abp.2015_1104

Reddy P, Edwards LR (2017) Magnesium Supplementation in vitamin D deficiency. Am J Ther. doi: 10.1097/MJT.0000000000000538

Reichrath J, Lehmann B, Carlberg C, Varani J, Zouboulis CC (2007) Vitamins as hormones. Hormone Metab Res 39: 71-84. doi: 10.1055/ s-2007-958715

Rejnmark L, Bislev LS, Cashman KD, Eiríksdottir G, Gaksch M, Grübler M, Grimnes G, Gudnason V, Lips P, Pilz S, Van Schoor NM, Kiely M, Jorde R (2017) Non-skeletal health effects of Vitamin D supplementation: A systematic review on findings from meta-Analyses summarizing trial data. PLOS ONE. doi: 10.1371/journal.pone.0180512

Samuel S, Sitrin MD (2008) Vitamin D s role in cell proliferation and differentiation. Nutrit Rev 66 (Suppl. 2): S116-S124. doi: 10.1111/j.1753-4887.2008.00094.x

Schwalfenberg G (2007) Not enough vitamin D: health consequences for Canadians. Canadian Family Phys Med Famille Canadien 53: 841854

Slominski A, Semak I, Zjawiony J, Wortsman J, Li W, Szczesniewski A, Tuckey RC (2005) The cytochrome P450scc system opens an alternate pathway of vitamin D3 metabolism. FEBS J 272: 4080 4090. doi: 10.1111/j.1742-4658.2005.04819.x

Slominski AT, Brozyna A, Jozwicki W, Tuckey RC (2015a) Vitamin D as an adjuvant in melanoma therapy. Melanoma Management 2: 1-4. doi: $10.2217 / \mathrm{mmt} .14 .36$

Slominski AT, Brożyna AA, Skobowiat C, Zmijewski MA, Kim T-K, Janjetovic Z, Oak AS, Jozwicki W, Jetten AM, Mason RS, Elmets C, Li W, Hoffman RM, Tuckey RC (2018) On the role of classi$\mathrm{cal}$ and novel forms of vitamin $\mathrm{D}$ in melanoma progression and management. I Steroid Biochem Mol Biol 177: 159-170. doi: 10.1016/j. jsbmb.2017.06.013

Slominski AT, Brożyna AA, Zmijewski MA, Jóźwicki W, Jetten AM, Mason RS, Tuckey RC, Elmets CA (2017a) Vitamin D signaling and melanoma: role of vitamin $\mathrm{D}$ and its receptors in melanoma progression and management. Lab Invest 97: 706-724. doi: 10.1038/ labinvest.2017.3 
Slominski AT, Janjetovic Z, Fuller BE, Zmijewski MA, Tuckey RC, Nguyen MN, Sweatman T, Li W, Zjawiony J, Miller D, Chen TC, Lozanski G, Holick MF (2010) Products of vitamin D3 or 7-dehydrocholesterol metabolism by cytochrome P450scc show anti-leukemia effects having low or absent calcemic activity. PLoS One 5: e9907. doi: 10.1371/journal.pone.0009907

Slominski AT, Kim T-K, Hobrath JV, Oak ASW, Tang EKY, Tieu EW, Li W, Tuckey RC, Jetten AM (2017b) Endogenously produced nonclassical vitamin D hydroxy-metabolites act as "biased" agonists on VDR and inverse agonists on ROR $\alpha$ and ROR $\gamma$. J Steroid Biochem Mol Biol 173: 42-56. doi: 10.1016/j.jsbmb.2016.09.024

Slominski AT, Kim T-K, Janjetovic Z, Tuckey RC, Bieniek R, Yue J, Li W, Chen J, Nguyen MN, Tang EKY, Miller D, Chen TC, Holick M (2011) 20-Hydroxyvitamin D 2 is a noncalcemic analog of vitamin $\mathrm{D}$ with potent antiproliferative and prodifferentiation activities in normal and malignant cells. Am J Physiol-Cell Physiol 300: C526C541. doi: 10.1152/ajpcell.00203.2010

Slominski AT, Kim T-K, Li W, Postlethwaite A, Tieu EW, Tang EKY, Tuckey RC (2015b) Detection of novel CYP11A1-derived secosteroids in the human epidermis and serum and pig adrenal gland. Sci Rep 5: 14875. doi: 10.1038/srep14875

Slominski AT, Kim T-K, Shehabi HZ, Semak I, Tang EKY, Nguyen MN, Benson HAE, Korik E, Janjetovic Z, Chen J, Yates CR, Postlethwaite A, Li W, Tuckey R. C (2012) In vivo evidence for a novel pathway of vitamin D 3 metabolism initiated by P450scc and modified by CYP27B1. FASEB J 26: 3901-3915. doi: 10.1096/ fj.12-208975

Slominski AT, Kim T-K, Takeda Y, Janjetovic Z, Brozyna AA, Skobowiat C, Wang J, Postlethwaite A, Li W, Tuckey RC, Jetten AM (2014) $\operatorname{ROR} \alpha$ and ROR $\gamma$ are expressed in human skin and serve as receptors for endogenously produced noncalcemic 20-hydroxy- and 20 23-dihydroxyvitamin D. FASEB J 28: 2775-2789. doi: 10.1096/ fj. $13-242040$

Slominski AT, Li W, Kim T-KK, Semak I, Wang J, Zjawiony JK, Tuckey RC (2015c) Novel activities of CYP11A1 and their potential physiological significance. I Steroid Biochem Mol Biol 151: 25-37. doi: 10.1016/j.jsbmb.2014.11.010

Slominski AT, Zmijewski MA, Semak I, Zbytek B, Pisarchik A, Li W, Zjawiony J, Tuckey RC (2014) Cytochromes p450 and skin cancer: role of local endocrine pathways. Anti-Cancer Agents Med Chem 14: 77-96. doi: 10.1016/j.immuni.2010.12.017.Two-stage

Sowah D, Fan X, Dennett L, Hagtvedt R, Straube S (2017) Vitamin D levels and deficiency with different occupations: a systematic review. BMC Public Health 17: 519. doi: 10.1186/s12889-017-4436-z

Suckow M, Stevens K, Wilson R (2012) The Laboratory Rabbit Guinea Pig Hamster and Other Rodents. American College of Laboratory Animal Medicine. 1st edn. Suckow M, Stevens K, Wilson R eds. doi: http:// dx.doi.org/10.1016/B978-0-12-380920-9.00001-8

Thacher TD, Clarke BL (2011) Vitamin D insufficiency. Mayo Clinic Proc 86: 50-60. doi: 10.4065/mcp.2010.0567

Venkatram S, Chilimuri S, Adrish M, Salako A, Patel M, Diaz-Fuentes $G$ (2011) Vitamin D deficiency is associated with mortality in the medical intensive care unit. Crit Care (London, England) 15: R292. doi: $10.1186 /$ cc10585

Virmani A (2014) Vitamin D toxicity. Indian Pediatrics 51: 63. doi: 10.1007/s13312-014-0315-1

Wacker M, Holick MF (2013) Sunlight and Vitamin D. Dermato-Endocrinol 5: 51-108. doi: 10.4161/derm.24494

Wang J, Slominski A, Tuckey RC, Janjetovic Z, Kulkarni A, Chen J, Postlethwaite AE, Miller D, Li W (2012) 20-hydroxyvitamin D inhibits proliferation of cancer cells with high efficacy while being non-toxic. Anticancer Res 32: 739-746

Weiss D, Wardrop J (2010) Schalm's Veterinary Hematology. 6th edn. Wardrop J, Weiss D eds. Wiley-Blackwell

Wierzbicka J, Piotrowska A, Zmijewski MA (2014) The renaissance of vitamin D. Acta Biochim Pol 61: 679-686

Yeh MW, Ituarte PHG, Zhou HC, Nishimoto S, Amy Liu I-L, Harari A, Haigh PI, Adams AL (2013) Incidence and prevalence of primary hyperparathyroidism in a racially mixed population. J Clin Endocrinol Metabol 98: 1122-1129. doi: 10.1210/jc.2012-4022 